\title{
Osteologia comparada entre as espécies de peixes-rei Odontesthes Evermann \& Kendall (Osteichthyes, Atherinopsidae) do sistema lagunar Patos-Mirim, no extremo sul do Brasil
}

\author{
Marlise de A. Bemvenuti \\ Departamento de Oceanografia, Fundação Universidade Federal do Rio Grande. Caixa Postal 474, 96201-900 Rio Grande, \\ Rio Grande do Sul, Brasil. E-mail docmab@furg.br
}

\begin{abstract}
Comparative osteology among the species of silverside Odontesthes Evermann \& Kendall (Osteichthyes, Atherinopsidae) in the Patos-Mirim lagoons systems, in the Southern of Brazil. An osteological comparison of seven species of silversides that occur from the Patos-Mirim lagoons systems is presented and discussed. Five species inhabit freshwater environments, Odontesthes bonariensis (Valenciennes, 1835), O. humensis De Buen, 1953, O. retropinnis (De Buen, 1953), O. perugiae Evermann \& Kendall, 1906, and O. mirinensis Bemvenuti, 1995. The other species, $O$. incisa (Jenyns, 1842) and O. argentinensis (Valenciennes, 1835), inhabit in coastal and brackish waters.

KEY WORDS. Atheriniformes, bone feature, morphology, taxonomy.
\end{abstract}

RESUMO. Uma comparação osteológica é apresentada e discutida entre sete espécies de peixes-rei que ocorrem no complexo lagunar Patos-Mirim, no extremo sul do Brasil. Cinco espécies habitam ambientes de água doce: Odontesthes bonariensis (Valenciennes, 1835), O. humensis De Buen, 1953, O. retropinnis (De Buen, 1953), O. perugiae Evermann \& Kendall, 1906, O. mirinensis Bemvenuti, 1995. Outras duas, O. incisa (Jenyns, 1842) e O. argentinensis (Valenciennes, 1835), ocorrem no estuário e na região costeira adjacente.

PALAVRAS CHAVE. Atheriniformes, caracteres ósseos, morfologia, taxonomia.

As espécies do gênero Odontesthes Evermann \& Kendall, 1906, conhecidas como peixes-rei, são encontradas na América do Sul em ambientes marinho, estuarino e de água doce (White 1985). Algumas espécies de peixes-rei são de grande porte, com tamanho variando entre 300 e $500 \mathrm{~mm}$ de comprimento total (CT). São importantes na pesca artesanal e muito utilizadas em aqüicultura, o que sugere um especial interesse pelo seu estudo biológico.

Ao longo dos anos, ocorreram freqüentes mudanças na classificação das espécies de peixes-rei, baseadas em dados morfológicos insuficientes para sua caracterização. O gênero Odontesthes foi definido por Jordan \& HubBs (1919) como tendo "pré-maxilares protráteis" em distinção a Basilichthys Girard, 1854, que não possui a boca protrátil. Whiтe (1985) ao caracterizar as espécies de peixes-rei considerou as do Atlântico Sul como Odontesthes e aquelas que ocorrem no Peru e Chile, em água doce, como Basilichthys. Este autor utilizou caracteres ósseos redefinindo a diagnose do gênero Odontesthes através da boca protrátil, opérculo com fenestras no ângulo antero dorsal e ausência do mesetmóide. Dyer (1997) no estudos das relações filogenéticas entre os Atheriniformes, acrescentou novos caracteres na diagnose do gênero, tais como, forame trigeminofacial coberto pelos ossos pró-ótico, esfenótico e pteroesfenoide, processos dorsal e ventral da cabeça do maxilar de mesmo comprimento, espinho hemal anterior pequeno. Análise de evolução molecular, biogeografia e especiação do gênero Odontesthes confirmaram que o grupo é monofilético, sendo as espécies derivadas do grupo marinho (BeHEREgaray \& SunNUCKS 2001).

Recentemente, as espécies do gênero Odontesthes foram analisadas com base nas relações fenéticas com diferenciação por morfometria multivariada (Bemvenuti 2002). A análise dos caracteres morfológicos em exemplares coletados no sistema lagunar Patos-Mirim, no extremo sul do Brasil, identificou a ocorrência de sete espécies do gênero Odontesthes. Cinco habitam ambientes de água doce, O. bonariensis (Valenciennes, 1835), O. humensis De Buen, 1953, O. retropinnis (De Buen, 1953), O. mirinensis Bemvenuti, 1995 e O. perugiae Evermann \& Kendall, 1906. As outras duas são O. incisa (Jenyns, 1842), marinha costeira e O. argentinensis (Valenciennes, 1835), estuarina marinha (Bemvenutr 2002). Alguns peixes-rei de menor porte, O. perugiae, $O$. mirinensis e $O$. argentinensis, mostraram grande semelhança morfológica. Sua identificação em nível específico foi possível somente através da morfometria multivariada e comparação dos caracteres ósseos (BEMVEnUti 1995, 1997). 
O propósito do presente trabalho foi apresentar uma comparação dos caracteres ósseos das espécies de Odontesthes que ocorrem no sistema lagunar Patos-Mirim, no extremo sul do Brasil.

\section{MATERIAL E MÉTODOS}

Os peixes-rei foram coletados em arroios, lagoas, estuários e costa adjacente, do sistema lagunar Patos-Mirim no extremo sul do Brasil, com redes de emalhar (espera) ou arrastos de praia e estão depositados na Coleção de Peixes da Fundação Universidade Federal do Rio Grande (FURG), Rio Grande do Sul.

Os exemplares menores foram diafanizados através da técnica de TaYlor (1967), modificada por PotThoff (1984), consistindo de várias etapas, entre as quais a digestão enzimática com tripsina e a coloração dos ossos com alizarina. No final do processo, o material foi dissecado e preservado em glicerina. Os esqueletos dos exemplares maiores foram obtidos pelo processo de limpeza com água fervente colocada sobre os peixes, após evicerados. Depois de retirada a musculatura, os ossos foram limpos e clareados em uma solução de $\mathrm{H}_{2} \mathrm{O}_{2}(3 \%)$ e $\mathrm{KOH}(2 \%)$, sendo preservados a seco. As ilustrações foram preparadas usandose câmara clara acoplada a um microscópio estereoscópio.

A terminologia adotada na caracterização das diversas estruturas apoiou-se nos trabalhos de Harrington (1955), White (1985), Chernoff (1986), Dyer \& Chernoff (1996), Dyer (1997), com adaptações à língua portuguesa em CASTRO \& CASTRO (1987).

Material examinado. Medidas em milímetros do comprimento padrão (cp):

O. argentinensis (6) - diafanizados: FURG 80.044 (90 mm cp) estuário da Lagoa dos Patos, RS, 18/I/1980; FURG 87.0207 (107 mm cp) idem 31/X/1980; FURG 87.0215 (138 mm cp) $25 \mathrm{~km}$ ao sul da Praia do Cassino, RS, II/1982; FURG 87.0216 (115 e 117 mm cp) estuário da Lagoa dos Patos, RS, 28/I/ 1987; esqueleto: FURG 87.0208 (200 mm cp) $25 \mathrm{~km}$ ao sul da Praia do Cassino, RS, II/1982.

O. bonariensis (3) - diafanizado: FURG 87.0041 (128 mm cp) Lagoa Mirim, RS, 20/X/1987; esqueletos: FURG 87.0212 (298 mm cp) idem 10/VI/1987; FURG 87.0209 (345 mm cp) idem 28/VIII/1987.

O. humensis (3) - diafanizados: FURG 87.0211(100,5 mm) Lagoa Mirim, RS, 5/X/1987; FURG 86.0003 (255 mm CP) Lagoa Mangueira, RS, VII/1986; FURG 97.0132 (198,7 mm cp) Lagoa Mirim, RS, 11/VII/1997; FURG 97.0133 (75,5 e 91 mm cp) Lagoa Mirim, RS, 31/VII/1997; esqueletos: FURG 87.0210 (267 mm cp) Lagoa Mirim, RS, 10/VI/1987; FURG 97.0132 (271 mm cp) Lagoa Mirim, RS, 11/VII/1997.

O. incisa (1) - diafanizado: FURG 79.0543 (77 mm cp) estuário da Lagoa dos Patos, RS, 7/VI/1979.

O. mirinensis (5) - diafanizados: FURG 87.0017 (87 mm cp) Lagoa Mirim, RS, 18/VII/1987; FURG 87.0119 (73,3 e 82,8 mm cp) idem 5/X/1987; esqueletos: FURG 87.0120 (295 mm cp) idem 10/VI/1987; FURG 88.0002 (120 mm cp) idem 29/XII/ 1988.

Revista Brasileira de Zoologia 22 (2): 293-305, junho 2005
O. perugiae (4) - diafanizados: FURG 87.0024 (213 mm cp) Lagoa Mangueira, RS, VII/1987; FURG 87.0065 (170 mm cp) idem VII/1987; FURG 87.0117 (192 mm cp) idem VII/1987; FURG 87.0118 (205 mm cp) idem VII/1987.

O. retropinnis (2) - diafanizado: FURG 87.0213 (225 mm cp) Lagoa Mangueira, RS, VII/1987; esqueleto: FURG 87.0214 (226 mm cp) idem 1/VII/1987.

\section{RESULTADOS E DISCUSSÃO}

A descrição osteológica é apresentada em três partes (crânio, esqueleto axial e esqueleto apendicular), mediante comparação entre as espécies $O$. argentinensis, O. bonariensis, $O$. humensis, O. incisa, O. mirinensis, O. perugiae e O. retropinnis.

\section{Crânio}

Neurocrânio apresenta a forma retangular (Figs 1-18), sendo mais largo na região occipital de O. humensis (Figs 6-7) e mais estreito e comprido em O. perugiae (Figs 14-15).

O etmóide mantém-se cartilaginoso durante o estágio adulto de alguns aterinídeos (CHERNoff 1986), bem como nas espécies estudadas. Apresenta a forma arredondada anteriormente, ocupando quase a metade do teto interno do crânio. Articula-se ventralmente, com o vômer e lateralmente com os etmóides laterais, estando os frontais situados dorsalmente. A borda anterior do etmóide tem o formato mais estreito em $O$. argentinensis (Fig. 1) e O. incisa (Fig. 9). O mesetmóide, encontrado nos demais gêneros da sub-família Atherinopsinae está ausente em Odontesthes (White 1985, Dyer 1997).

Os etmóides laterais formam as paredes mediano-laterais do etmóide e articulam-se anteriormente com o vômer. Em posição ventral tem a forma arredondada, sendo que em $O$. argentinensis, O. humensis e O. retropinnis, a projeção póstero dorsal é mais alongada (Figs 2, 7, 17). Os etmóides laterais possuem uma projeção externa que dá suporte ao primeiro infraorbital (IO1-lacrimal), característica comum para o gênero Odontesthes (DYER 1997).

A face anterior do vômer é estreita e está coberta dorsalmente pelo etmóide. Na extremidade anterior ocorrem projeções laterais bem desenvolvidas na forma de uma meia-lua, mais largas em O. bonariensis, O. mirinensis e O. perugiae (Figs 5, $12,15)$. Articula-se firmemente com o paresfenóide em posição póstero ventral. Entre as espécies de Odontesthes a presença de dentes no vômer é variável (DYER 1997). Em O. argentinensis e O. bonariensis (Figs 2, 5) estão arranjados em uma placa mediana, em O. perugiae (Fig. 15) formam três placas separadas. Nas demais espécies os dentes do vômer estão ausentes. Dyer (1997) registrou dentes dispostos em uma placa mediana em $O$. incisa e em três placas em O. argentinensis.

Os nasais localizam-se lateralmente na região etmoidal, têm a borda interna em forma de um tubo completo, por onde passa parte do canal sensorial supra-orbital (DYER 1997). Ligam-se aos infra-orbitais, através de uma projeção ventral, característica da subfamília Atherinopsinae (White 1985, Dyer 1997) (Fig. 19). 

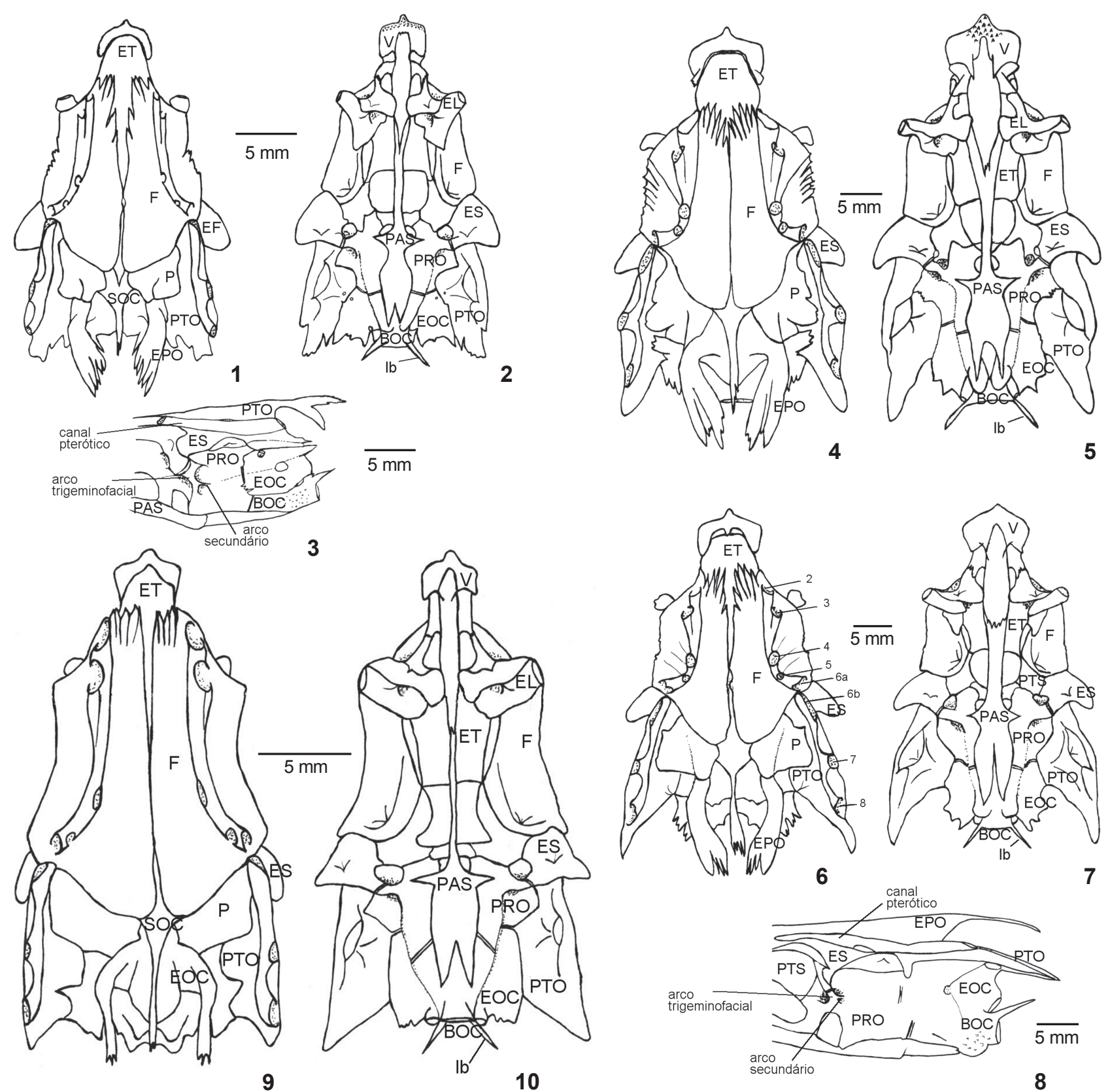

Figuras 1-10. Neurocrânio: vista dorsal, ventral e lateral: (1-3) Odontesthes argentinensis; (4-5) O. bonariensis; (6-8) O. humensis; (9-10) O. incisa. (2-8) Poros do canal sensorial supra-orbital, (ET) etmóide, (EL) etmóide lateral, (V) vômer, (F) frontal, (PAS) paresfenóide, (BAS) basiesfenóide, (PTS) pteroesfenóide, (P) parietal, (ES) esfenótico, (PTO) pterótico, (EPO) epoccipital, (PRO) pró-ótico, (EOC)exoccipital, (BOC) basioccipital, (SOC) supra-occipital, (ft) forame trigeminofacial, (lb) ligamento de Baudelot.

Os esfenóticos estão situados entre os frontais e os pteróticos. Todos os exemplares analisados apresentaram a mesma forma ovalada, característica observada também em Basilichthys australis Eigenmann, 1928 (De La Hoz \& Tosti-Croce 1981).

Os pteróticos possuem uma depressão ventral onde se articula uma das cabeças do hiomandibular. Apresentam sobre sua face dorsal dois poros do canal sensorial supra-orbital, iniciado no frontal (White 1985, Dyer 1997) (Fig. 6).

Os epoccipitais estão circundados pelo supra-occipital, parietais, pteróticos e exoccipitais. Sobre eles apóia-se firme-

Revista Brasileira de Zoologia 22 (2): 293-305, junho 2005 


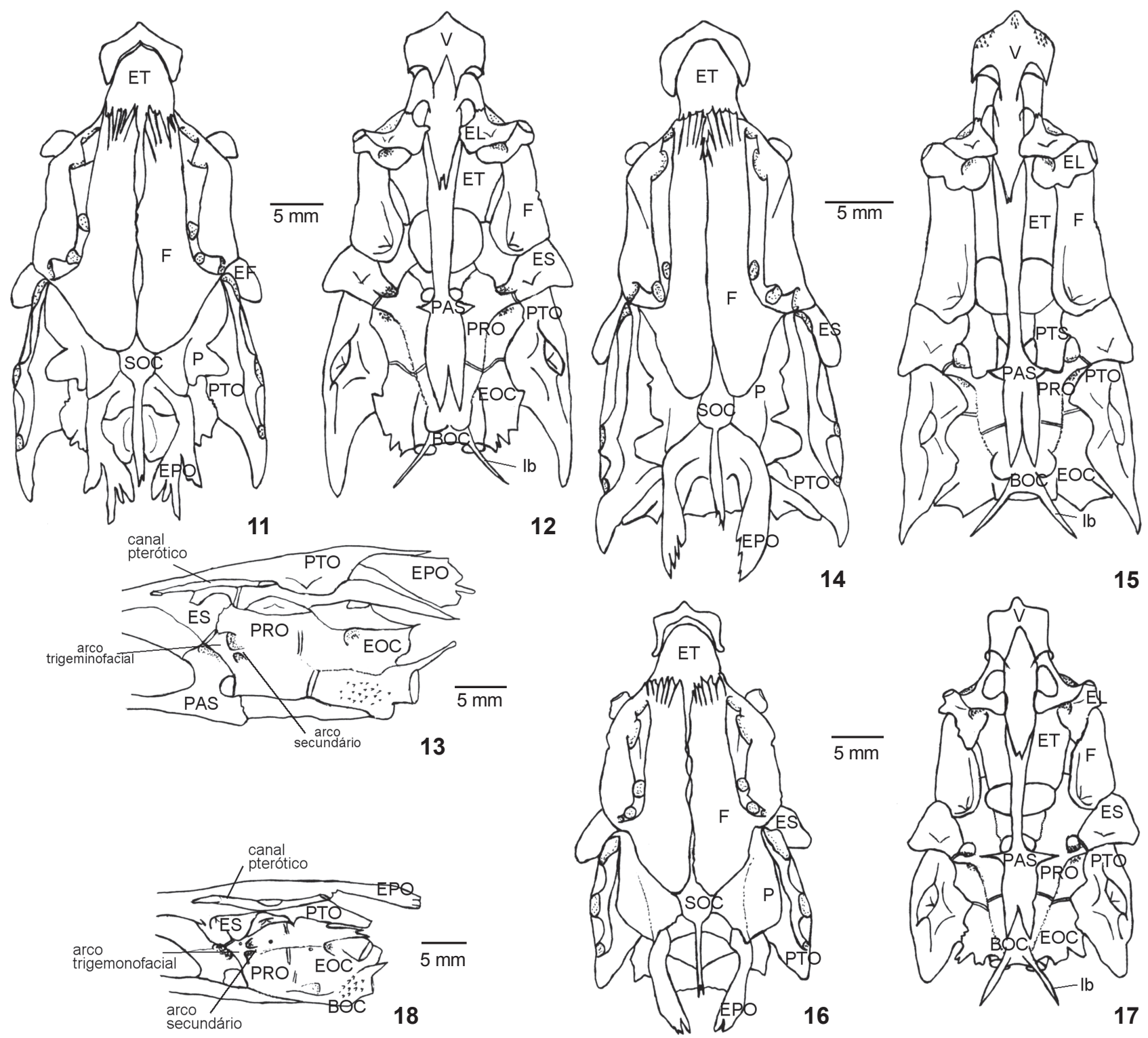

Figuras 11-18. Neurocrânio: vista dorsal, ventral e lateral: (11-13) O. mirinensis; (14-15) O. perugiae; (16-18) O. retropinnis. (2-8) Poros do canal sensorial supra-orbital, (ET) etmóide, (EL) etmóide lateral, (V) vômer, (F) frontal, (PAS) paresfenóide, (BAS) basiesfenóide, (PTS) pteroesfenóide, (P) parietal, (ES) esfenótico, (PTO) pterótico, (EPO) epoccipital, (PRO) pró-ótico, (EOC)exoccipital, (BOC) basioccipital, (SOC) supra-occipital, (ft) forame trigeminofacial, (lb) ligamento de Baudelot.

mente a porção anterior do processo superior dos pós-temporais, conectando a cintura peitoral ao crânio. A projeção posterior alargada dos epoccipitais apresenta muitos recortes, sendo mais estreita e lisa em O. incisa e O. retropinnis (Figs 9, 16).

Os pró-oticos possuem um forame trigeminofacial que cruza o osso por entre suas asas laterais, através de um arco principal com ampla abertura ântero-dorsal. $\mathrm{O}$ forame envolve também, o esfenótico e o pteroesfenóide, característica comum em Odontesthes Dyer (1997). Além do arco principal, também foi observado um arco secundário incompleto, considerado por Dyer (1997) como característica comum aos Atherinopsidae, não encontrado nos demais Atheriniformes (Figs 3, 8, 13, 18).

O basioccipital tem a forma de um " $U$ " invertido, com projeções laterais que se expandem até encontrarem o paresfenóide anteriormente, com o qual se conecta. Posteriormente, as projeções se fusionam formando uma base circular côn- 

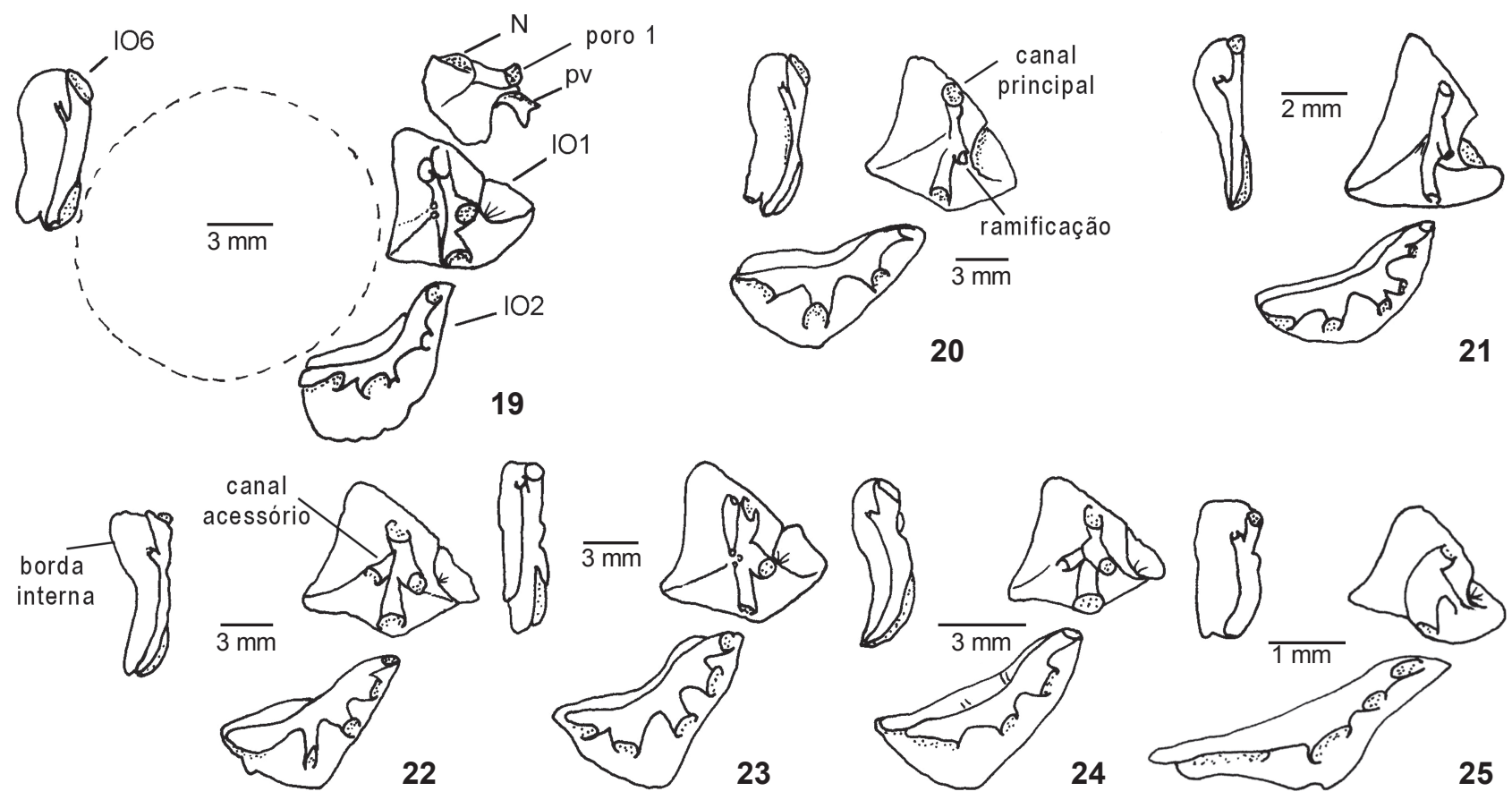

Figuras 19-25. Série infra-orbital, vista externa do lado direito: (19) O. retropinnis, (20) O. bonariensis, (21) O. argentinensis, (22) O. humensis, (23) O. mirinensis, (24) O. perugiae, (25) O. incisa. (N) Nasal, (IO1) infra-orbital 1 (lacrimal), (IO2) infra-orbital 2, (IO6) infraorbital 6 (dermoesfenótico), (pv) processo ventral, poro 1 do canal supra-orbital.

cava que faz a articulação com o centro da primeira vértebra. Estas projeções laterais do basioccipital são esculpidas por uma série de pequenos e irregulares sulcos ou fenestras (Figs 3, 8, $13,18)$, característica dos peixes-rei Atherinopsinae sul-americanos (WHITE 1985, Dyer 1997). As projeções do basioccipital são maiores em $O$. bonariensis, O. humensis, O. mirinensis, $O$. perugiae (Figs $5,7,8,12,13,15$ ) e pouco visíveis em $O$. argentinensis, O. incisa e O. retropinnis (Figs 2, 3, 10, 17, 18). No basioccipital observa-se uma estrutura em forma de espinho fino, chamada "ligamento de Baudelot", ossificada nos Atherinopsinae (White 1985, Dyer 1997).

Os frontais ocupam grande área dorsal do neurocrânio, cobrindo externamente a órbita. Estão posicionados, posteriormente, ao etmóide e etmóides laterais, anteriormente ao supra-occipital, cobrindo-o parcialmente. Em posição pósterolateral estão os esfenóticos e parietais. As bordas centrais dos frontais estão parcialmente separadas por uma fontanela craniana, cujo contato se dá apenas na região mediana em $O$. argentinensis, $O$. humensis e $O$. incisa (Figs 1, 6, 9). O contato é maior em $O$. bonariensis $e O$. perugiae, ocupando quase toda a extensão dorsal (Figs 4, 14). Em O. mirinensis a sutura ocorre em duas partes e O. retropinnis em três (Figs 11, 16).

Na superfície dorsal dos frontais localiza-se o canal sensorial supra-orbital de forma curva para os lados, com cinco poros, característica dos Atherinopsinae (White 1985, Dyer
1997). De acordo com Dyer (1997) os poros do canal supraorbital iniciam no nasal (poro 1), seguem o frontal (2 a 6) e continuam no pterótico (6 a 8) (Fig. 6). White (1985) contou sete poros no canal supra-orbital, por não ter incluído o poro 1 do nasal. Os exemplares examinados possuem um total de oito poros no canal supra-orbital, um poro nasal, cinco poros do frontal e dois do pterótico (Fig. 6).

O paresfenóide é um osso longo de posição ventral conectado entre o vômer e o basioccipital. Sua ligação com o vômer, anteriormente, é estreita, em forma de "V", em $O$. argentinensis e O. incisa (Figs 2, 10) e mais larga em O. mirinensis, O. perugiae e O. retropinnis (Figs 12, 15, 17). Esta ligação mais larga tem aspecto levemente serrilhado em O. bonariensis e fortemente serrilhado em O. humensis (Figs 5, 7). Posteriormente, a extremidade distal bifurca-se em dois prolongamentos que vão além da metade do basioccipital. Em sua posição mediana apresenta uma estrutura em forma de asas laterais.

O basiesfenóide tem a forma de "Y", conectado dorsalmente aos pró-óticos e pteroesfenóides. Ventralmente estende-se em direção ao paresfenóide com o qual se conecta através de expansões ósseas, sem diferenças entre os peixes-rei estudados.

Os infra-orbitais formam a série de ossos dérmicos inferiores ao bordo do olho, associados ao canal sensorial infraorbital. Chernoff (1986) classificou os peixes-rei do Velho Mun- 

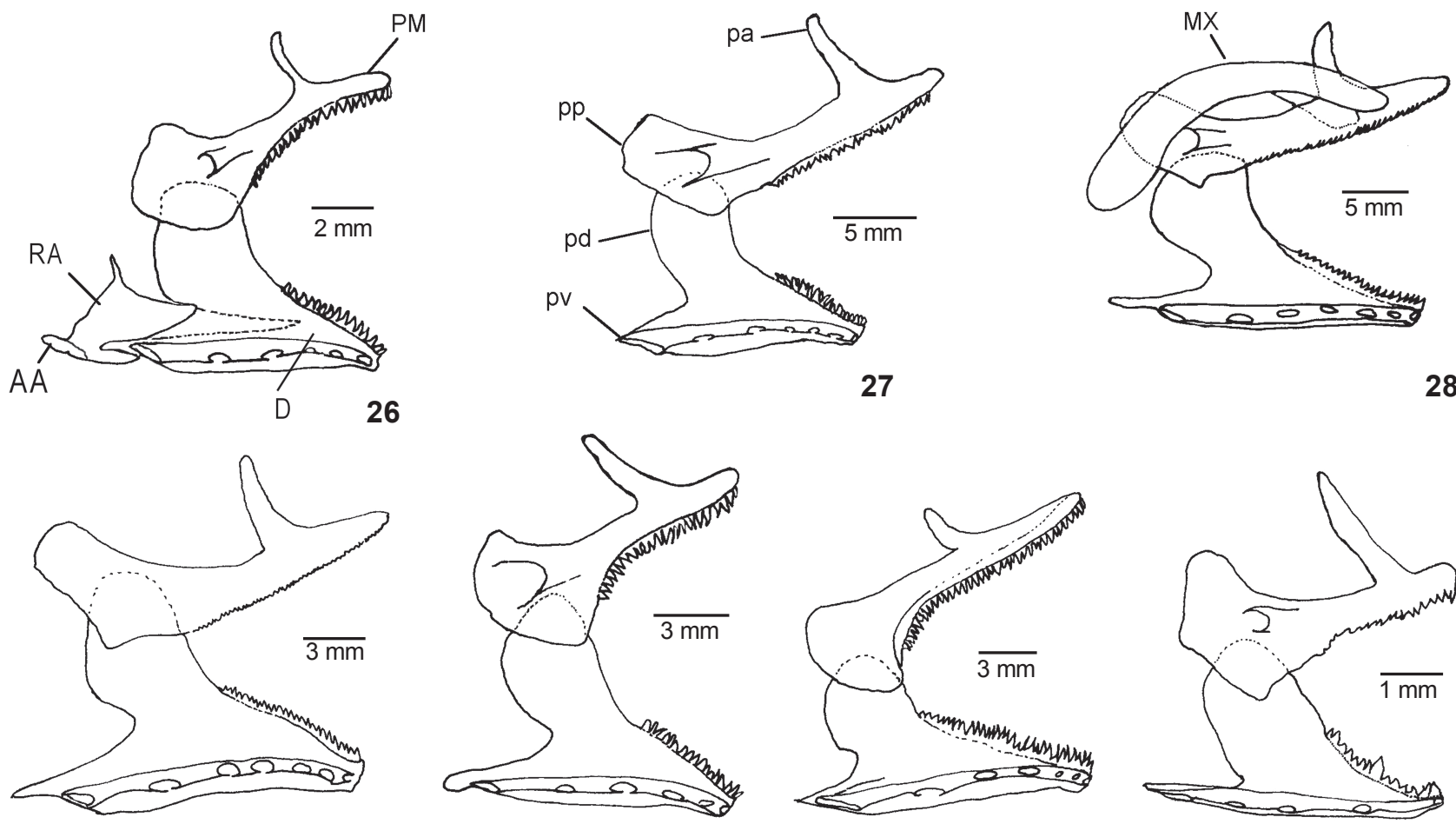

30
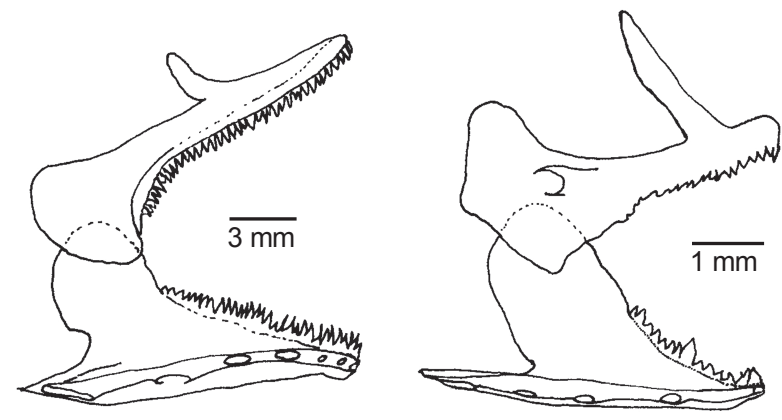

31

32

Figuras 26-32. Estrutura da boca, vista externa do lado direito: (26) O. bonariensis, (27) O. humensis, (28) O. mirinensis, (29) O. retropinnis, (30) O. argentinensis, (31) O. perugiae, (32) O. incisa. (MX) Maxilar, (PM) pré-maxilar, (D) dentário, (RA) retroarticular, (AA) ânguloarticular, (pa) processo ascendente, (pp) processo posterior, ( $\mathrm{pd}$ ) processo dorsal, (pv) processo ventral.
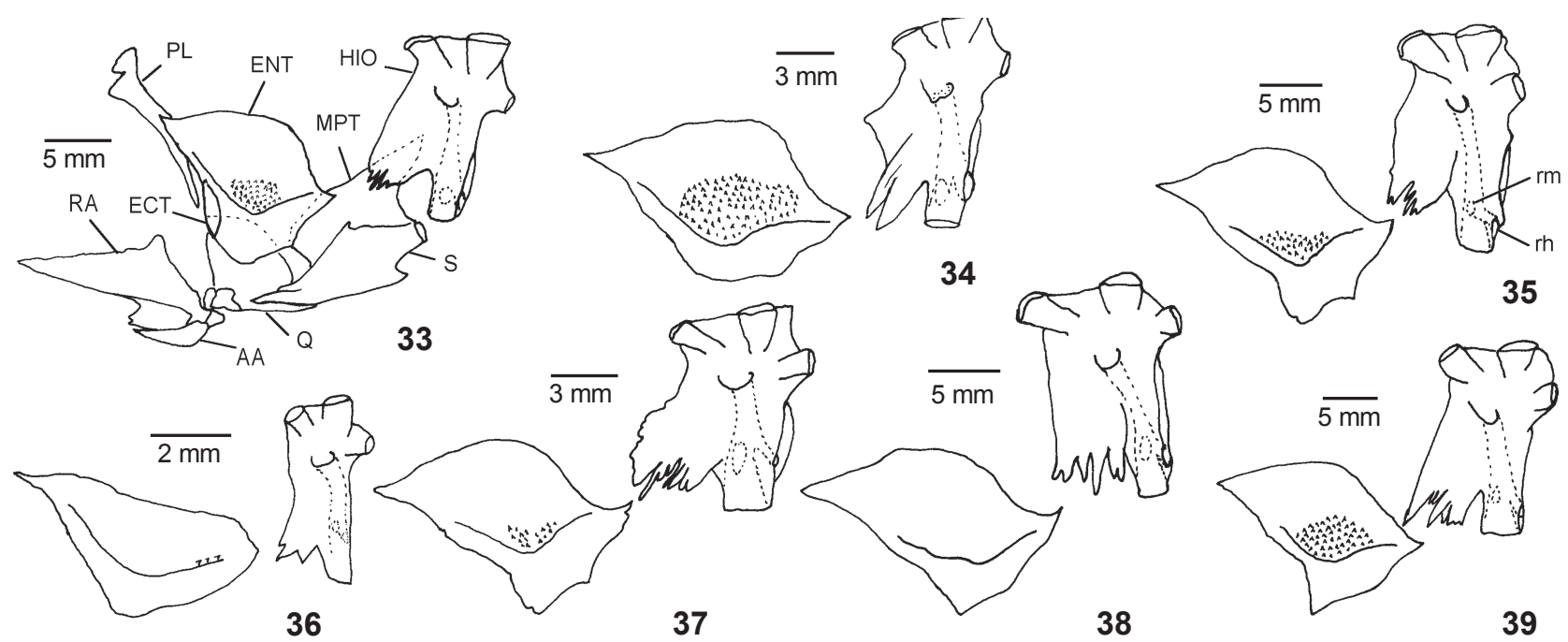

Figuras 33-39. Suspensório da mandíbula, vista interna do lado direito: (33) O. retropinnis, (34) O. argentinensis, (35) O. bonariensis, (36) O. incisa, (37) O. perugiae, (38) O. humensis, (39) O. mirinensis. (HIO) Hiomandibular, (ENT) endopterigóide, (ECT) ectopterigóide, (MPT) metapterigóide, (PL) palatino, (RA) retroarticular, (AA) ângulo-articular, (Q) quadrado, (S) simplético, (rm) ramificação mandibular, (rh) ramificação hióidea.

Revista Brasileira de Zoologia 22 (2): 293-305, junho 2005 


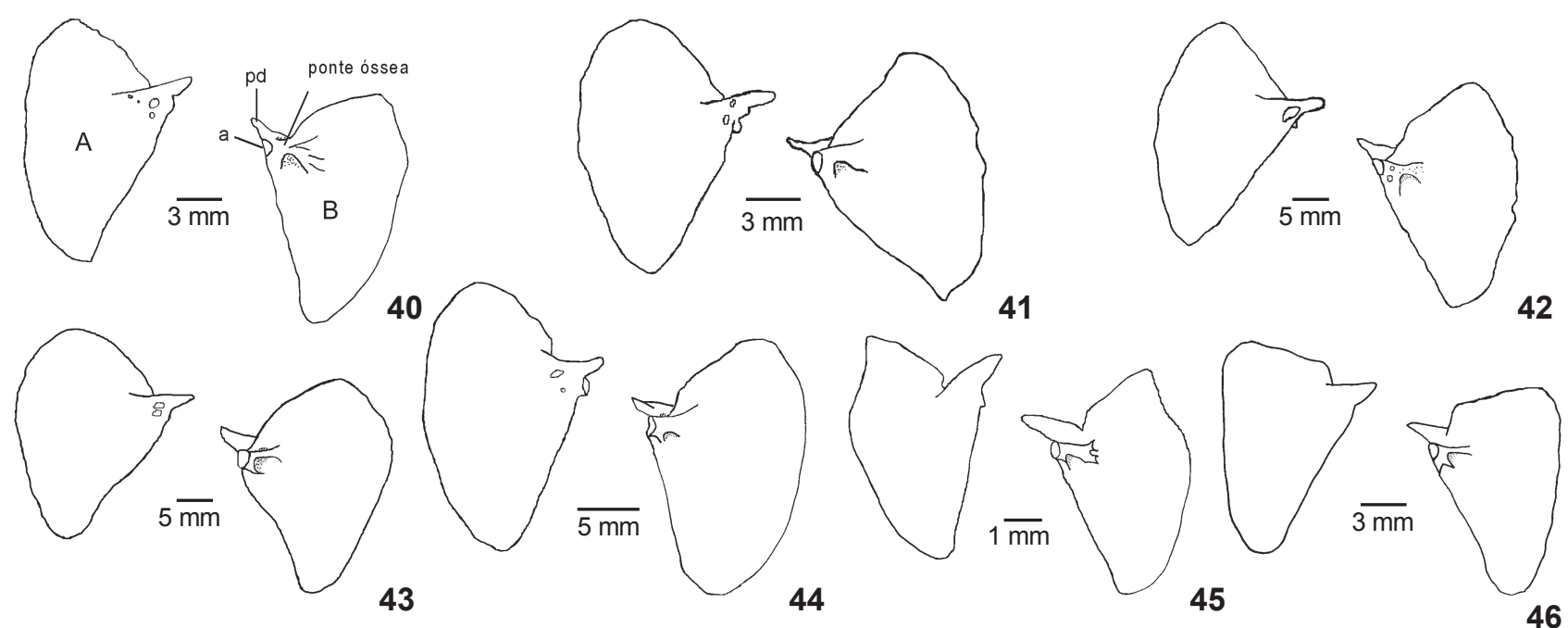

Figuras 40-46. Opérculo, vista interna (a) externa (b) do lado direito: (40) O. argentinensis, (41) O. bonariensis, (42) O. humensis, (43) O. mirinensis, (44) O. retropinnis (45) O. incisa, (46) O. perugiae. (pd) Processo dorsal, (a) articulação com o hiomandibular.
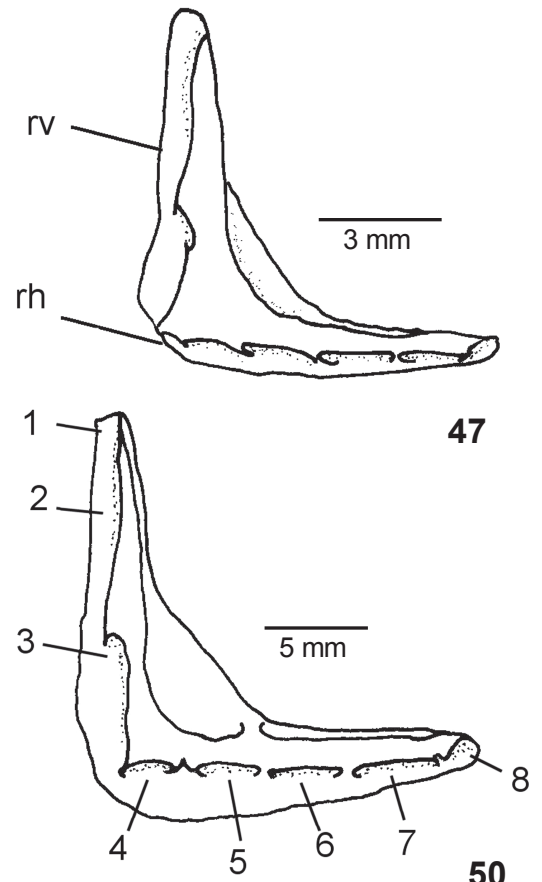

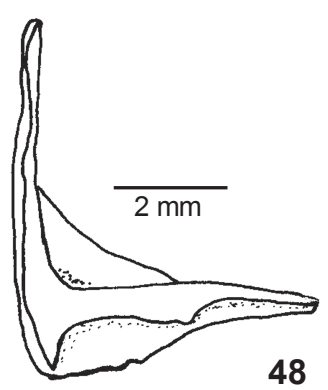

48
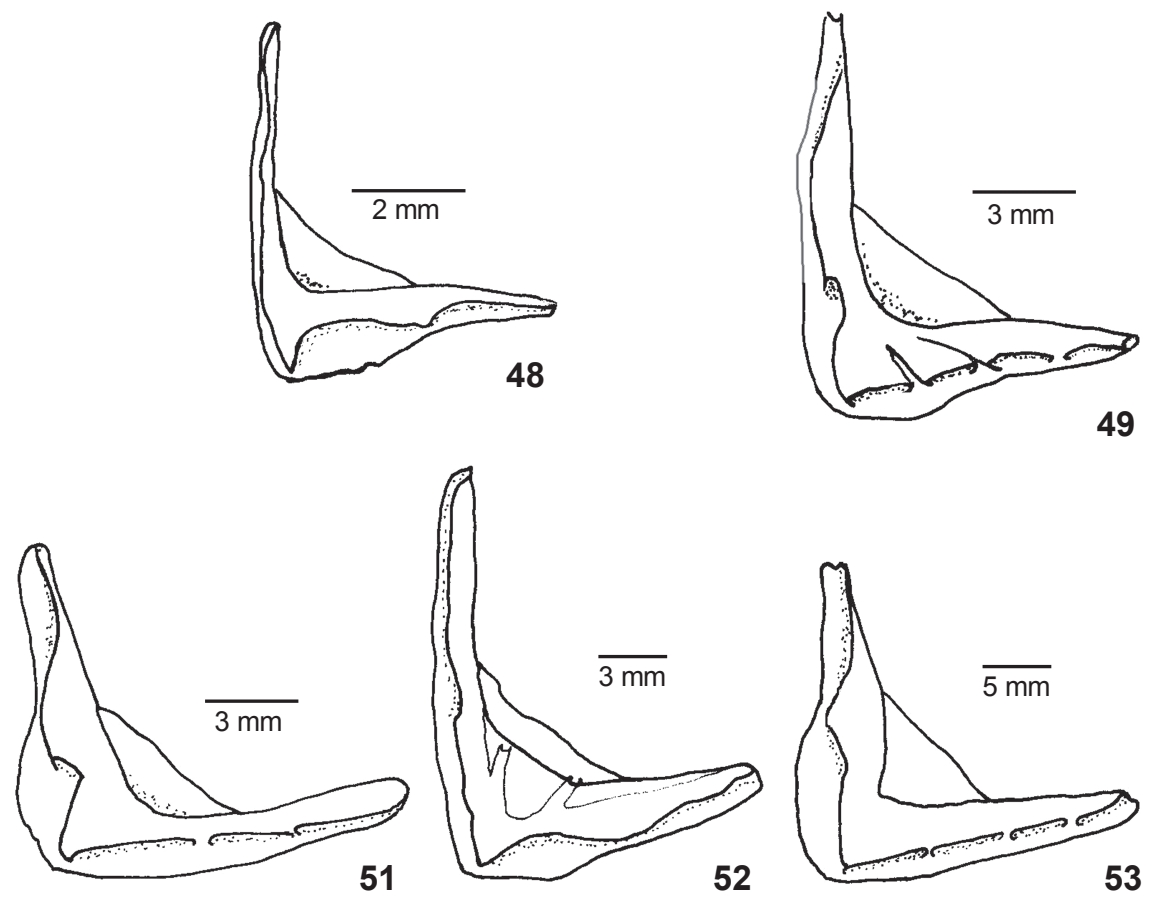

53

Figuras 47-53. Pré-opérculo, vista externa do lado direito: (47) O. humensis, (48) O. incisa, (49) O. bonariensis, (50) O. retropinnis, (51) O. argentinensis, (52) O. perugiae, (53) O. mirinensis. (rv) Ramificação vertical, (rh) ramificação horizontal do canal sensorial, (1-8) poros do canal sensorial.

do, com poucas exceções, como tendo três ossos infra-orbitais anteriores e os do Novo Mundo com dois ossos anteriores. Os peixes-rei examinados apresentam dois ossos infra-orbitais anteriores e um posterior, com canais sensoriais alojados em tubos principais e acessórios com seus respectivos poros (Figs 19-25).

O infra-orbital 1, também chamado lacrimal tem posição ântero superior à órbita. Nas espécies examinadas, o infraorbital 1 possui um canal sensorial principal com uma ramifi-

Revista Brasileira de Zoologia 22 (2): 293-305, junho 2005 


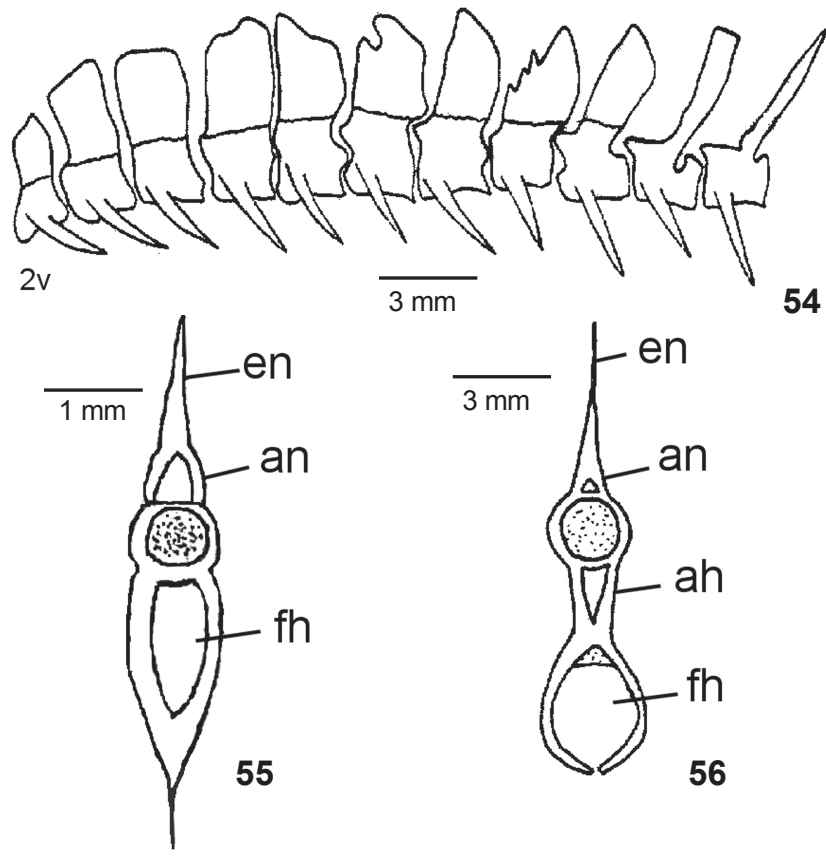

Figuras 54-56. (54) Vértebras pré-caudais, vista esquerda a partir da $2^{\text {a }}$ vértebra dos primeiros espinhos neurais modificados, formando uma lâmina vertical em 0 . argentinensis; (55-56) vértebra caudal, vista frontal em: (55) O. incisa; (56) Atherinops affinis (extraída de WHITE, 1985). (fh) Funil hemal, (ah) arco hemal, (an) arco neural, (en) espinho neural.

cação menor, resultando em três poros. Um canal acessório, independente do principal, foi observado em O. humensis e $O$. perugiae (Figs 22, 24), com um poro interno e outro externo, em O. retropinnis e O. mirinensis com dois poros externos (Figs $19,23)$, sendo que em O. retropinnis há um orifício junto a um dos poros externos. O canal acessório está ausente em $O$. bonariensis, O. argentinensis e O. incisa (Figs 20, 21, 25).

O infra-orbital 2 situa-se abaixo da órbita e articula-se anteriormente com o IO1. Tem a forma triangular com um canal principal dorsal e alguns canais acessórios perpendiculares. Em O. argentinensis (Fig. 21) são quatro canais acessórios longos com seis poros totais, em O. humensis e O. mirinensis são três canais (Figs 22, 23). Em O. retropinnis, O. bonariensis, $O$. perugiae e $O$. incisa são dois canais acessórios com quatro poros (Figs 19, 20, 24, 25), sendo que em $O$. bonariensis são compridos e nos demais são bem curtos.

O terceiro osso da série infra-orbital, denominado dermoesfenótico, tem posição pós-orbital e permanece ligado ao crânio na porção dorsal. É um osso plano, exceto em O. perugiae que é curvo ventralmente (Fig. 24). Possui um canal sensorial de posição dorso-ventral. O poro dorsal do dermoesfenótico conecta-se ao poro seis do canal sensorial supra-orbital (DYER 1997). Um canal menor na parte superior foi observado em todas as espécies. A borda estreita ao longo da face interna do dermoesfenótico foi apresentada por DYER (1997) como característica comum para Atheriniformes, condição observada em O. mirinensis e O. perugiae (Figs 23, 24). Em O. argentinensis e $O$. humensis a borda é mais larga no terço superior (Figs 21, 22) e, em $O$. retropinnis, $O$. bonariensis e $O$. incisa a borda larga ocupa todo seu comprimento (Figs 19, 20, 25).

\section{Branquiocrânio}

O pré-maxilar é um osso curvo com dois processos: o ascendente (pa) que resulta na protratibilidade da boca (Rosen 1964, Alexander 1967) e o processo posterior (pp) (Figs 26-32). O processo ascendente é fino, comprido e dirigido para frente. É o local de encaixe do maxilar, que gira como um eixo, quando faz a protusão da boca. Tem o formato de gancho em todas as espécies, com exceção de $O$. incisa de formato reto (Fig. 32) $\mathrm{O}$ processo ascendente é mais pronunciado em $O$. bonariensis e de menor tamanho em O. perugiae (Figs 26, 31). O processo posterior foi denominado por Dyer (1997) de "parte distal do braço alveolar do pré-maxilar", considerando a porção distal notavelmente dilatada como condição derivada para Atherinopsidae. O processo posterior dirige-se para cima em todas as espécies, sendo mais elevado em $O$. humensis e O. retropinnis (Figs 27, 29). Em O. perugiae o processo posterior dirige-se para baixo (Fig. 31).

Na porção inferior do pré-maxilar estão várias fileiras de dentes curtos inseridos desordenadamente e dirigidos para trás. As fileiras de dentes atingem até quase o final do processo posterior em O. mirinensis e O. perugiae (Figs 28, 31), diminuindo sua extensão em $O$. bonariensis, O. humensis, O. retropinnis e $O$. argentinensis (Figs 26, 27, 29, 30). As fileiras de dentes são bem mais curtas em $O$. incisa, ultrapassando um pouco a metade do pré-maxilar (Fig. 32). O maxilar é um osso achatado e retorcido ao longo de seu comprimento. A forma côncava do maxilar na extremidade dorsal é evidente nas espécies com pré-maxilar protrátil (Rosen 1964). A porção anterior é separada em duas partes e está assentada sobre o processo ascendente do prémaxilar. A porção posterior apóia-se sobre a superfície externa do mesmo osso. Os peixes-rei analisados apresentaram semelhante morfologia no osso maxilar, como desenhado em $O$. mirinensis (Fig. 28).

O dentário apresenta uma estrutura tubular que aloja, na região ventral, o canal sensorial mandibular, com uma série de poros de número variável. Em O. humensis, O. mirinensis, $O$. retropinnis e O. perugiae há sete poros totais (Figs 27-29, 31), em $O$. bonariensis e $O$. argentinensis, seis poros (Figs 26, 30) e em $O$. incisa, cinco poros (Fig. 32). Na margem anterior desenvolvemse duas fileiras irregulares de dentes, com exceção de O. perugiae e O. retropinnis que possuem três fileiras. Em O. incisa ocorrem alguns dentes caninos entre as duas fileiras de dentes (Fig. 32). Em O. perugiae a banda de dentes é mais extensa do que nas demais espécies examinadas atingindo o processo dorsal (Fig. $31)$.

A extremidade posterior do dentário apresenta os pro- 

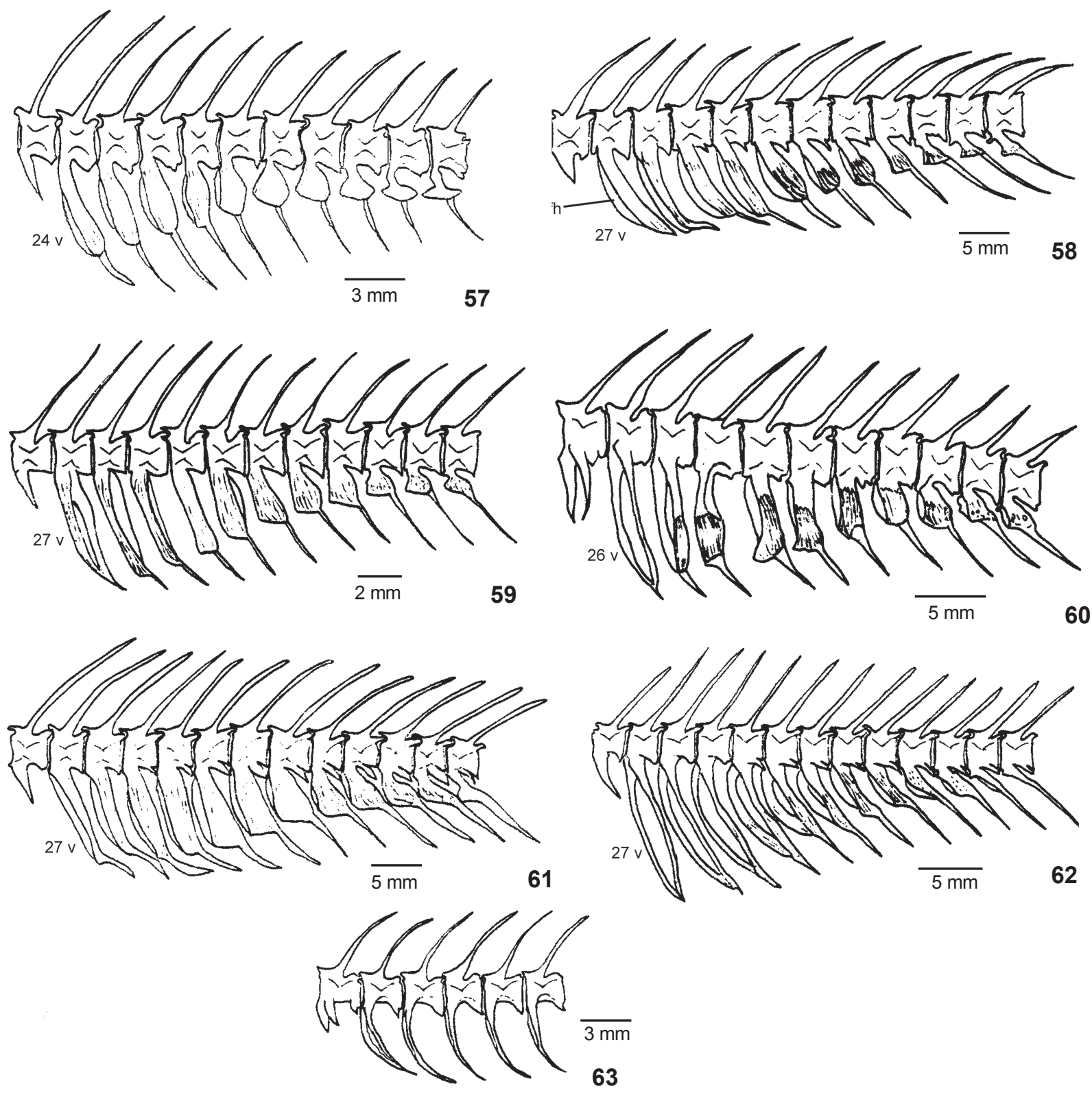

Figuras 57-63. Vértebras Caudais: vista esquerda das primeiras vértebras caudais; (57) O. argentinensis, (58) O. humensis, (59) O. bonariensis, (60) O. perugiae, (61) O. mirinensis, (62) O. retropinnis, (63) O. incisa; fh funil hemal.

cessos dorsal e ventral. O processo dorsal, também chamado processo coronóide (DYER 1997) é usualmente arredondado com uma projeção dorsal mais elevada em O. retropinnis (Fig. 29). O processo ventral prolonga-se em ponta fazendo o encaixe com o retroarticular, ligados entre si através da cartilagem de Meckel. O processo ventral é mais pronunciado em O. incisa (Fig. 32). No ângulo póstero inferior do retroarticular ocorre o encaixe da cabeça de articulação do quadrado. O quadrado tem a for- ma triangular, com um grande processo dirigido para trás cobrindo parte do simplético (Fig. 33).

O hiomandibular apresenta três cabeças de articulação em sua parte dorsal, articuladas anteriormente com as áreas escavadas do esfenótico, do pterótico e posteriormente com o opérculo (Figs 33-39). A parte ventral do hiomandibular liga-se ao metapterigóide e ao simplético (Fig. 33). Na face interna há um forame superior que permite a passagem do nervo

Revista Brasileira de Zoologia 22 (2): 293-305, junho 2005 

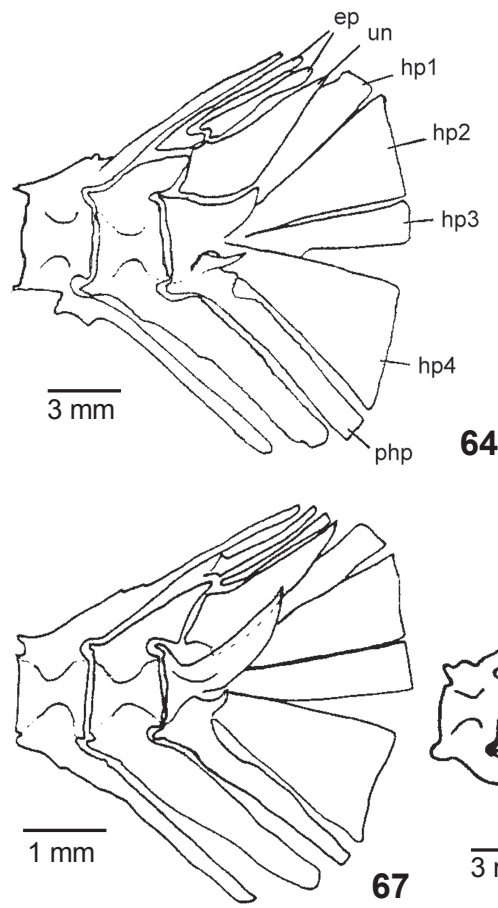
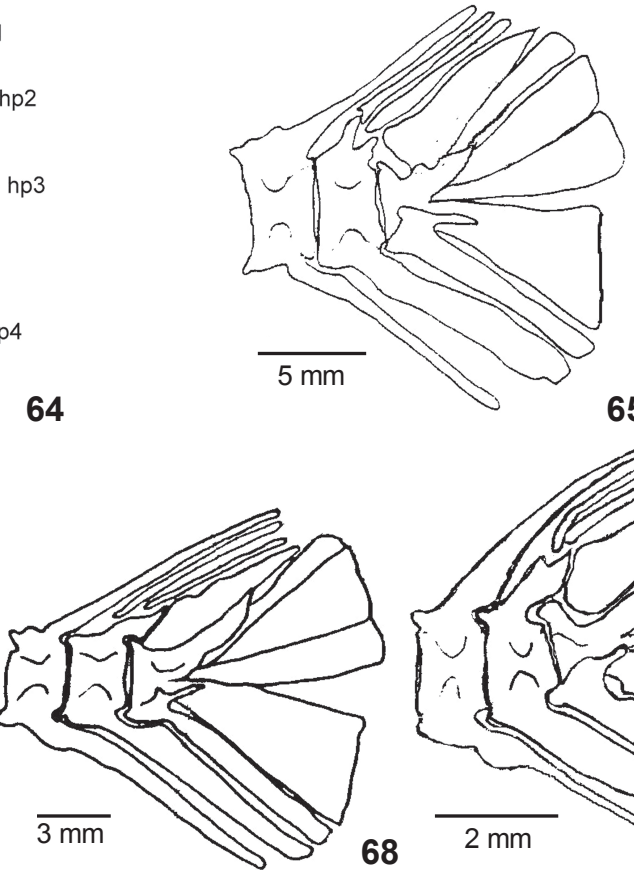

65

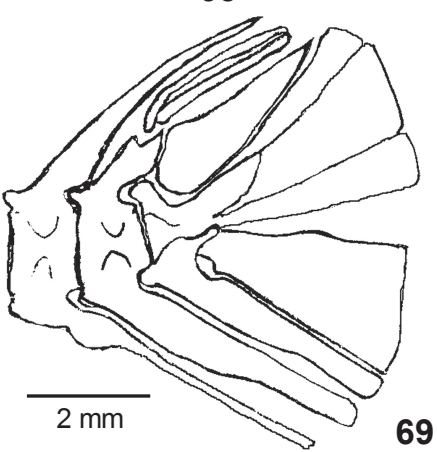

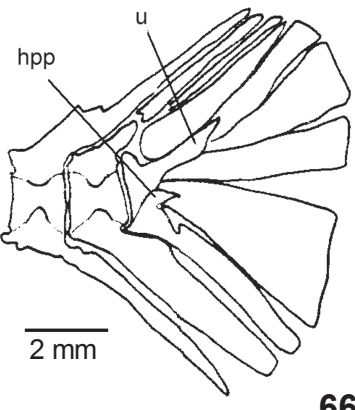

66

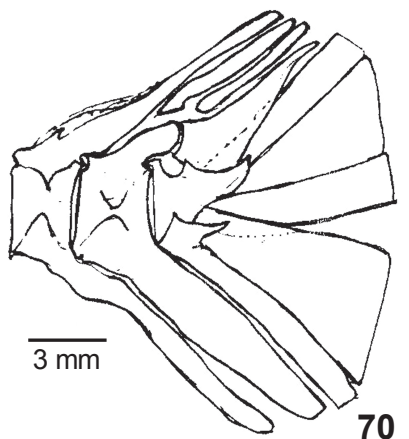
mirinensis, (69) O. bonariensis, (70) O. retropinnis. (ep) Epurais, (un) uroneural, (hp1-hp4) hipurais, (php) paripural, (u) uróstilo, (hpp) hipurapófise.

hiomandibular, de um lado a outro do osso, dividindo-se em ramificação mandibular e hióidea. Esta divisão dentro do hiomandibular foi citada por DYER (1997), como condição derivada para as espécies de Odontesthes, com exceção de O. hatcheri (Eigenmann, 1909). A ramificação mandibular abre-se ao exterior através de um poro na face externa do hiomandibular e a ramificação hióidea é visível pela face interna do osso, em posição bem lateral (Fig. 35). Em O. retropinnis, O. argentinensis e $O$. incisa as duas ramificações têm o mesmo comprimento (Figs $33,34,36$ ) e os poros o mesmo diâmetro, enquanto que em $O$. bonariensis, $O$. perugiae e $O$. humensis a ramificação hióidea é mais comprida (Figs 35, 37, 38). Em O. mirinensis o orifício da ramificação mandibular está em posição mais elevada, apresentando um diâmetro bem menor (Fig. 39).

O endopterigóide é um osso fino de grande tamanho estendendo-se na base da órbita. Sua borda posterior une-se por sutura ao metapterigóide, enquanto a borda anterior conecta-se ao palatino, quadrado e ectopterigóide, que é muito pequeno (Fig. 33). A borda inferior curva possui dentes, ausentes apenas em O. humensis (Fig. 38). Os dentes estão em grande quantidade em $O$. argentinensis e O. mirinensis (Figs 34, 39), enquanto em $O$. retropinnis, $O$. bonariensis, O. perugiae e há poucos dentes (Figs $33,35,37)$. Em $O$. incisa foram observados apenas três dentes pequenos, junto à curvatura póstero inferior do osso (Fig. 36).

O opérculo é um osso largo, laminar, levemente triangu- lar. Na parte superior há uma ossificação arredondada chamada processo dorsal, característica dos Atheriniformes (Dyer 1997), abaixo do qual uma estrutura escavada suporta a cabeça de articulação do hiomandibular (Figs 40-46). No ângulo ânterodorsal da face interna do opérculo ocorrem fenestras, que podem ser vistas, também pela face externa, através de dois ou mais poros em O. argentinensis, O. bonariensis, O. mirinensis e O. retropinnis (Figs 40, 41, 43, 44), enquanto em O. humensis (Fig. 42) há apenas um poro. As fenestras estão ausentes em O. incisa (Dyer 1997) e em O. perugiae (Figs 45, 46).

O pré-opérculo tem a forma de um "L", conectado ao hiomandibular em sua porção superior e ao quadrado na porção inferior. $O$ canal sensorial, parcialmente ossificado, percorre o osso formando um ângulo reto (Figs 47-53). A ramificação vertical, parcialmente fechada tem três poros, sendo que os poros 1 e 2 não apresentam ponte óssea como separação, sendo esta uma característica comum para as espécies de Odontesthes (DYER 1997). A ramificação vertical apresentou-se totalmente aberta em O. incisa (Fig. 48). A presença de cinco poros na ramificação horizontal é uma característica considerada comum para os Atherinopsidae (DYER 1997). Foram observados cinco poros em $O$. humensis, O. bonariensis, O. retropinnis e O. mirinensis (Figs 47, 49, 50, 53), enquanto em O. argentinensis (Fig. 51) foram contados quatro poros largos devido à ausência de ponte óssea entre os poros 5 e 6 . A ramificação horizontal é 

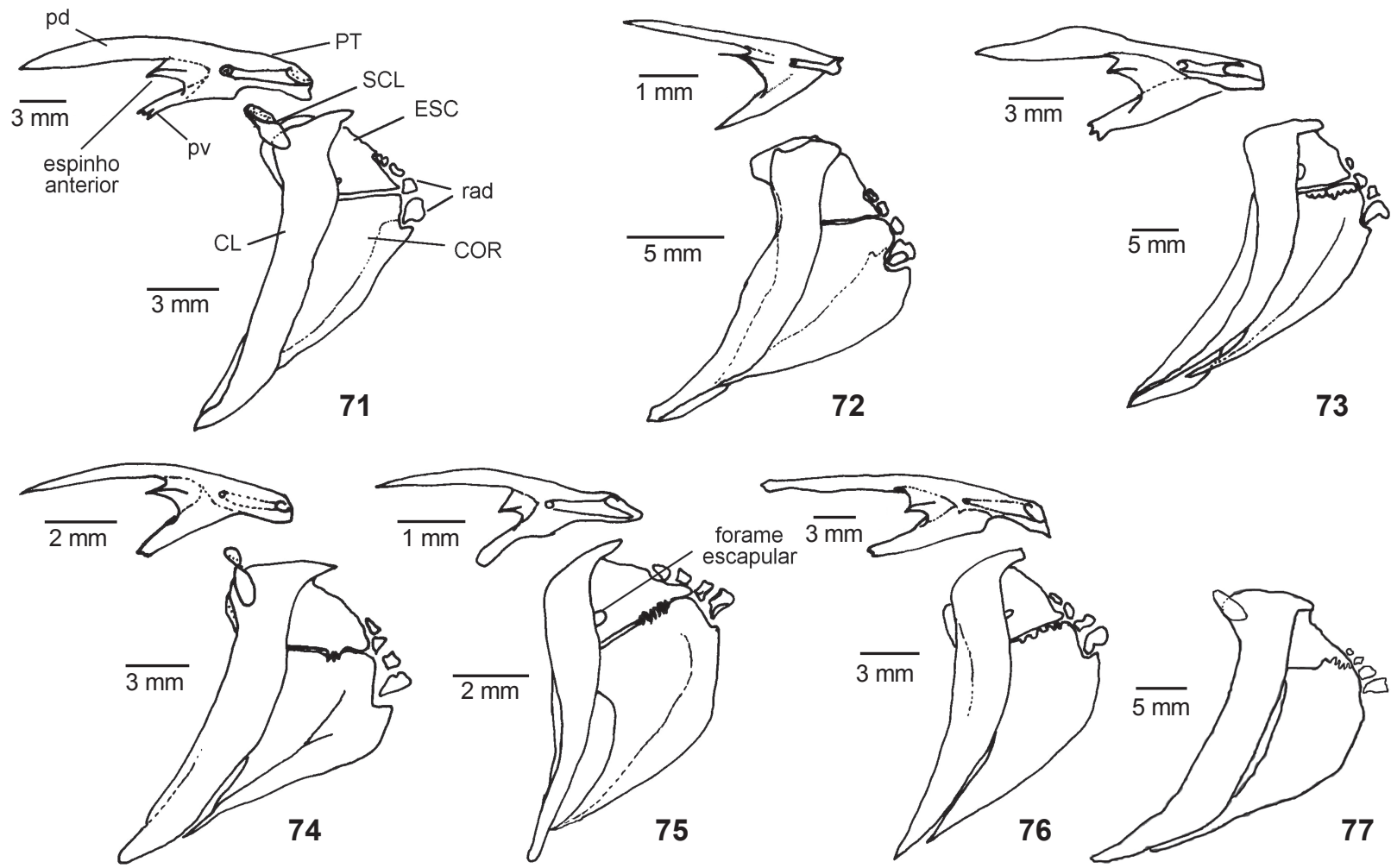

Figuras 71-77. Cintura peitoral, vista externa do lado esquerdo: (71) O. humensis, (72) O. incisa, (73) 0. retropinnis, (74) 0. argentinensis, (75) O. mirinensis, (76) O. bonariensis, (77) O. perugiae. (PT) Pós-temporal, (CL) cleitro, (SCL) supracleitro, (ESC) escápula, (COR) coracóide, (rad) radiais, $(\mathrm{pd})$ processo dorsal, $(\mathrm{pv})$ processo ventral.

relativamente pouco ossificada, sem pontes ósseas parecendo um canal aberto em O. incisa e O. perugiae. (Figs 48, 52).

\section{Esqueleto Axial}

Os primeiros espinhos neurais da coluna vertebral (segunda à oitava vértebras) são curtos, comprimidos e alargados lateralmente, formando uma sólida lâmina vertical, que dá sustentação à cabeça do peixe (Fig. 54). MARrero (1950) denominou esta estrutura de "ariete cervical", presente naqueles peixes que ele chamou de "laterinos", Austroatherina incisa. Todas as espécies examinadas apresentaram essa característica, variando apenas o tamanho dos espinhos neurais modificados.

$\mathrm{O}$ número total de vértebras das espécies examinadas variou entre 46 e 48 . As vértebras pré-caudais foram em número maior do que as caudais em O. bonariensis, O. humensis, $O$. mirinensis, O. perugiae e O. retropinnis e, em menor número em O. incisa. Esta característica foi discutida por DYer (1997) como sendo comum aos Atherinopsinae. Em O. argentinensis a contagem de vértebras foi semelhante entre as pré-caudais e caudais. Coincidentemente as primeiras espécies são todas de água doce, O. incisa é estritamente marinha e O. argentinensis é estuarinomarinha.

As primeiras vértebras caudais apresentam uma expan- são do arco hemal formando um funil hemal, por onde se prolonga a bexiga gasosa (Fig. 55). Essa modificação do arco hemal é característica dos peixes-rei da América do Sul, contrastando com aqueles da América do Norte, por exemplo Atherinops affinis (Ayres, 1860), cujo funil hemal se desenvolve a partir da bifurcação do espinho hemal (White 1985) (Fig. 56).

Em O. argentinensis, O. humensis, O. bonariensis, O. perugiae e O. mirinensis o funil hemal apresenta paredes largas (Figs 5761). Em O. retropinnis as paredes laterais dos arcos hemais são estreitas, ficando distantes uma da outra (Fig. 62). Em O. incisa os arcos hemais expandidos também possuem paredes laterais bem estreitas, apesar de Marrero (1950) e Dyer (1997) terem observado a ausência do funil hemal nesta espécie (Fig. 63). A partir da terceira ou quarta vértebra caudal forma-se uma projeção anterior, junto à base do espinho de maneira que os arcos hemais em $O$. humensis, $O$. bonariensis, O. perugiae e $O$. mirinensis ficam próximos uns dos outros (Figs 58-61). Em $O$. argentinensis a expansão é anterior e posterior (Fig. 57).

Em O. argentinensis e $O$. mirinensis o espinho das três primeiras vértebras do funil hemal é bem desenvolvido formando uma estrutura diferenciada do arco hemal (Figs 57, 61), enquanto em $O$. humensis, $O$. bonariensis e $O$. perugiae o espinho hemal é curto (Figs 58-60) e em O. retropinnis e O. incisa não há

Revista Brasileira de Zoologia 22 (2): 293-305, junho 2005 


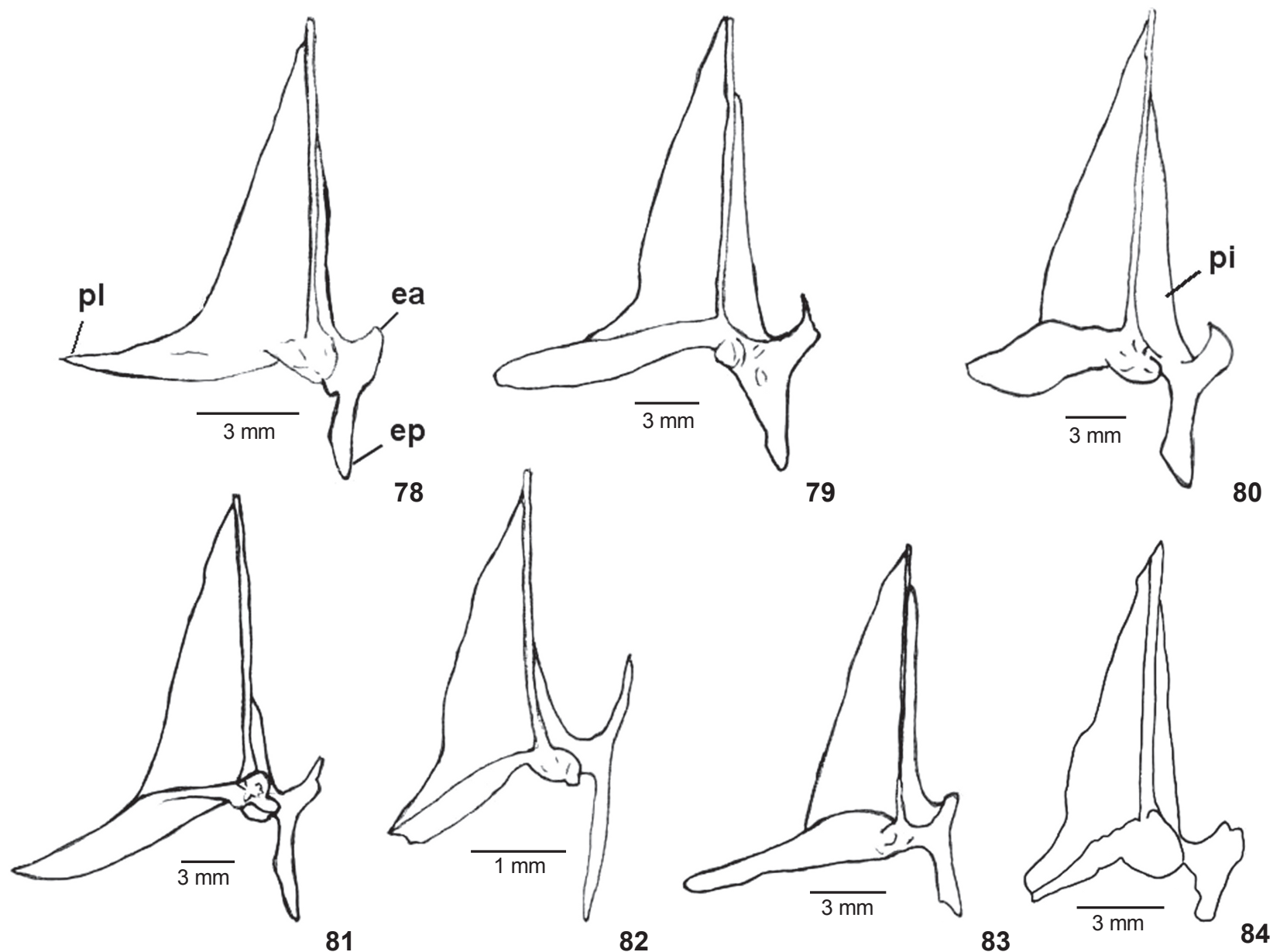

Figuras 78-84. Cintura pélvica, vista ventral do lado esquerdo: (78) O. perugiae, (79) O. bonariensis, (80) O. humensis, (81) O. mirinensis, (82) O. incisa, (83) O. argentinensis, (84) O. retropinnis. (pi) Placa interna, (pl) processo lateral, (ea) espinho anterior, (ep) espinho posterior.

espinho diferenciado (Figs 62, 63). Dyer (1997) registrou um espinho hemal curto em O. retropinnis e ausência de espinho e funil hemal em $O$. incisa.

A nadadeira caudal é formada por quatro hipurais, três superiores à linha média do corpo e um inferior, todos ligados ao centro da vértebra terminal (Figs 64-70). O paripural é alargado na base, estreitando-se para a extremidade na maioria das espécies. Junto à região anterior do paripural, está o processo em forma de gancho retorcido chamado de hipurapófise, que cobre a base do $4^{\circ}$ hipural, servindo para prender parte do músculo caudal (NuRsall 1963). Em O. perugiae o hipurapófise é mais comprido (Fig. 65) e em O. argentinensis é mais curto (Fig. 66). Os peixes-rei possuem apenas um uroneural parcialmente fusionado à placa hipural superior (hp1). Os dois epurais existentes representam vestígios da ossificação do espinho neural, ausente na última vértebra (Rosen 1964). O uróstilo forma uma projeção posterior mais longa em O. argentinensis, $O$. incisa e O. mirinensis (Figs 66-68) e mais curta em O. humensis e
O. retropinnis, em relação às demais espécies (Figs 64, 70).

\section{Esqueleto Apendicular}

A superfície anterior do cleitro apresenta-se relativamente larga, com borda lateral convexa, dando-lhe a forma de meialua (Figs 71-77). A escápula e o coracóide formam a parte posterior da cintura peitoral na qual o cleitro atua como suporte. A sutura óssea entre escápula e coracóide é reta em O. humensis e $O$. incisa (Figs 71, 72). Em O. retropinnis a sutura é denteada onde a escápula avança sobre o coracóide (Fig. 73), enquanto em $O$. argentinensis, $O$. mirinensis, $O$. bonariensis e $O$. perugiae o aspecto denteado só é visível no centro da sutura (Figs 74-77).

Os pós-temporais possuem duas ossificações anteriores, o processo dorsal que faz a conexão com o epoccipital e o processo ventral com o exoccipital (Figs 71-76). Entre os dois processos há uma ossificação semelhante a um espinho de comprimento variável, presente em todas as espécies, cujo maior tamanho foi encontrado em O. incisa (Fig. 72). De acordo com

Revista Brasileira de Zoologia 22 (2): 293-305, junho 2005 
Chernoff (1986), esse espinho anterior ocorre somente nos peixes-rei do Novo Mundo. Dyer (1997) considerou este espinho ausente em $O$. humensis.

As nadadeiras pélvicas são sustentadas internamente por dois ossos de forma triangular, articulados entre si na porção anterior mediana (Figs 78-84). A placa interna aos dois ossos não alcança o final do osso pélvico considerada característica comum aos Atheriniformes, com algumas exceções (DYER \& Chernoff 1996). A placa interna ultrapassa a metade do osso em O. perugiae, O. bonariensis, O. humensis, O. argentinensis e $O$. retropinnis (Figs 78-80, 83, 84), enquanto em O. mirinensis e $O$. incisa a placa é menor, equivalendo a um terço do osso (Figs $81,82)$. O espinho mediano anterior tem a forma de gancho bem pronunciado em O. bonariensis, O. humensis, O. mirinensis e O. incisa (Figs 79-82), enquanto em O. perugiae, O. argentinensis e $O$. retropinnis a projeção é curta (Figs $78,83,84$ ). O espinho mediano posterior é mais comprido em $O$. mirinensis e $O$. incisa (Figs 81, 82) e mais curto em O. retropinnis (Fig. 84) em relação aos demais. O processo lateral termina em ponta alongada em O. perugiae, O. humensis, O. mirinensis e O. argentinensis (Figs $78,80,81,83)$. Em O. bonariensis, O. incisa e O. retropinnis a ponta do processo lateral apresenta-se truncada e mais curta (Figs 79, 82, 84).

\section{REFERÊNCIAS BIBLIOGRÁFICAS}

AleXANDER, R.McM. 1967. Mechanisms of the jaws of some atheriniform fish. Journal Zoology, London, 151: 233-255.

Beheregaray, L.B. \& P. Sunnucks. 2001. Fine-scale genetic structure, estuarine colonization and incipient speciation in the marine silverside fish Odontesthes argentinensis. Molecular Ecology, Oxford, 10: 2849-2866.

Bemvenuti, M.A. 1995. Odontesthes mirinensis sp. n. um novo peixe-rei (Pisces, Atherinopsinae) para o extremo sul do Brasil. Revista Brasileira de Zoologia, Curitiba, 12 (4): 881-903.

Bemvenuti, M.A. 1997. Relações morfológicas e osteológicas entre Odontesthes perugiae e O. mirinensis (Teleostei: Atherinidae, Atherinopsinae). Atlântica, Rio Grande, 19: 73-92.

Bemvenuti, M.A. 2002. Diferenciação morfológica das espécies de peixes-rei Odontesthes Evermann \& Kendall (Osteichthyes, Atherinopsidae) no extremo sul do Brasil: morfometria multivariada. Revista Brasileira de Zoologia, Curitiba, 19 (1): 251-287.

Castro, R.M.C. \& M.M.C. Castro. 1987. Proposta de uma nomenclatura osteológica para Characiformes (Pisces: Ostario- physi). Boletim do Museu Paraense Emílio Goeldi, Série Zoologia, Belém, 3 (1): 25-32.

Chernoff, B. 1986. Phylogenetic relationships and reclassification of Menidiinae silverside fishes with emphasis of the tribe Membradini. Proceedings of the Academy of Natural Sciences of Philadelphia, Philadelphia, 138 (1): 189249.

De La Hoz, E. \& A.E. Tosti-Croce. 1981. Osteologia de Basilichthys australis Eigenmann (Teleostei, Atherinidae). Anales del Museo de Historia Natural, Valparaiso, 14: 229-245.

Dyer, B.S. 1997. Phylogenetic revision of Atherinopsinae (Teleostei, Atherinopsidae), with comments on the systematics of the South American freshwater fish genus Basilichthys Girard. Miscellaneous Publications Museum of Zoology, University of Michigan, Ann Arbor, (185): 1-64.

DYer, B.S. \& B. Chernoff. 1996. Phylogenetic relationships among atheriniform fishes (Teleostei: Atherinomorpha). Zoological Journal of the Linnean Society, London, 117: 1-69.

Harrington, R.W. 1955. The osteocranium of the American cyprinid fish Notropis bifrenatus, with na annotated synonymy of teleost skull bones. Copeia, Lawrence, (4): 267-290.

Jordan, D.S. \& C.L. Hubbs. 1919. Studies in Ichthyology. A monographic review of the family of Atherinidae or silversides. Stanford, Leland Stanford Jr. University Publications, 87p.

Marrero, A. 1950. Flechas de Plata. Atherinidos argentinos pejerreys y laterinos. Buenos Aires, Ed. Breitman, 157p.

NuRSALL, J.R. 1963. The hypurapophysis, an important element of the caudal skeleton. Copeia, Lawrence, (2): 458-459.

Potтhoff, T. 1984. Clearing and staining techniques, p. 35-37. In: H.G. Moser; W.J. Richards, D.M. Cohen, M.P. FaHAY, A.W. KeNDALL JR. \& S.L. RichaRdSON (Eds). Ontogeny and systematics of fishes. Lawrence, American Society of Ichthyologists and Herpetologists, Special Publication, \# 1, 759p.

Rosen, D.E. 1964. The relationships and taxonomic position of the halfbeaks, killifishes, silversides and their relatives. Bulletin American Museum Natural History, New York, 127 (5): 219-267.

TAYLOR, W.R. 1967. An enzyme method of clearing and staining small vertebrates. Proceedings of the United States National Museum, Washington, 122 (3596): 1-17.

White, B.N. 1985. Evolutionary relationships of the Atherinopsinae (Pisces: Atherinidae) Contribution in Sciences, Natural History Museum, Los Angeles, (368): 1-20.

Recebido em 26.II.2004; aceito em 11.III.2005.

Revista Brasileira de Zoologia 22 (2): 293-305, junho 2005 